\title{
X-Ray Videomicroscopy Studies of Eutectic Al-Si Solidification in Al-Si-Cu
}

\author{
R.H. MATHIESEN, L. ARNBERG, Y. LI, V. MEIER, P.L. SCHAFFER, I. SNIGIREVA, \\ A. SNIGIREV, and A.K. DAHLE
}

\begin{abstract}
Al-Si eutectic growth has been studied in-situ for the first time using X-ray video microscopy during directional solidification (DS) in unmodified and $\mathrm{Sr}$-modified Al-Si-Cu alloys. In the unmodified alloys, $\mathrm{Si}$ is found to grow predominantly with needle-like tip morphologies, leading a highly irregular progressing eutectic interface with subsequent nucleation and growth of Al from the $\mathrm{Si}$ surfaces. In the Sr-modified alloys, the eutectic reaction is strongly suppressed, occurring with low nucleation frequency at undercoolings in the range $10 \mathrm{~K}$ to $18 \mathrm{~K}$. In order to transport $\mathrm{Cu}$ rejected at the eutectic front back into the melt, the modified eutectic colonies attain meso-scale interface perturbations that eventually evolve into equiaxed compositestructure cells. The eutectic front also attains short-range microscale interface perturbations consistent with the characteristics of a fibrous $\mathrm{Si}$ growth. Evidence was found in support of $\mathrm{Si}$ nucleation occurring on potent particles suspended in the melt. Yet, both with Sr-modified and unmodified alloys, Si precipitation alone was not sufficient to facilitate the eutectic reaction, which apparently required additional undercooling for $\mathrm{Al}$ to form at the Si-particle interfaces.
\end{abstract}

DOI: $10.1007 / \mathrm{s} 11661-010-0443-8$

(C) The Author(s) 2010. This article is published with open access at Springerlink.com

\section{INTRODUCTION}

AL-BASE alloys constitute more than 50 pct of the commercial market for non-ferrous casting alloys, with hypo- to hypereutectic variants from the Al-Si system having a dominant share. Alloying with $\mathrm{Si}$ has a profound effect on the castability of $\mathrm{Al}$, promoting fluidity and feeding, and improved resistance toward casting defects such as porosity and hot tearing. Si alloying also contributes to reducing the specific weight and thermal expansion. Commercial Al-Si casting alloys contain a substantial fraction of eutectic. The Al-Si eutectic is an archetype of a so-called irregular eutectic, where the fcc Al phase, with a relatively modest crystalline anisotropy and a low melting entropy, grows nonfaceted, whereas $\mathrm{Si}$, which bonds covalently in a strongly anisotropic tetrahedral arrangement, is associated with a higher melting entropy and grows faceted along specific crystallographic directions. ${ }^{[1]}$

Despite the commercial importance of irregular eutectics, such as Al-Si and Fe-C, the literature available

R.H. MATHIESEN, Associate Professor, Department of Physics, and L. ARNBERG, Professor, Department of Material Science, are with NTNU, N-7491 Trondheim, Norway. Contact e-mail: ragnvald. mathiesen@ntnu.no Y. LI, Research Scientist, is with SINTEF Materials \& Chemistry, N-7465 Trondheim, Norway. V. MEIER, formerly Student, Department of Physics, NTNU, is Postdoctoral Student, with the Institut fur Strukturphysik, Technical University Dresden, D-01060 Dresden, Germany. P.L. SCHAFFER, Research Scientist, is with Norsk Hydro Sunndalsora, N-6600 Sunndalsora, Norway. I. SNIGIREVA and A. SNIGIREV, Reserach Scientists, are with the Experiments Division, ESRF, F-38043 Grenoble, France. A.K. DAHLE, Professor, is with the Department of Materials Engineering, University of Queensland, Brisbane QLD 4072, Australia. Manuscript submitted January 14, 2010.

Article published online October 19, 2010 on their solidification microstructure formation is limited compared to the vast amount available for regular eutectics. For the latter, constitutive relations exist to relate the solidification microstructures of regular lamellar and rodlike eutectics to experimental parameters. Within the operation limits of quasi-planar nearisothermal interface propagation, the pattern selection that defines the regular eutectic growth morphologies is fairly well described by the Jackson-Hunt model, ${ }^{[2,3]}$ and more recent extensions to this, e.g., by phase field simulations and experiments with transparent analogues, for growth behavior beyond the basic state interface stability limits. ${ }^{[4-6]}$

The growth mechanisms of irregular eutectics are inherently more complex. Generally, the faceted phase has restricted branching ability, and consequently, progression in three dimensions is considerably more cumbersome than for a nonfaceted component. The difference in branching ability, or solid-liquid interface stiffness, also implies that the two eutectic phases have different capabilities to adapt to varying growth conditions, and generally the faceted phase tends to grow at a higher undercooling than the nonfaceted phase, leaving the eutectic interface to progress in a nonisothermal manner. Fisher and Kurz ${ }^{1]}$ made the first attempts at deriving a constitutive two-dimensional (2-D) model for irregular eutectic growth by an extension of the Jackson-Hunt model, ${ }^{[2]}$ applying isothermal coupling conditions over local regions of the interface in order to bypass the difficulties of handling the dynamics of a nonisothermal front. Magnin and $\mathrm{Kurz}^{[7]}$ generalized to a full nonisothermal treatment with a 2-D model that later was modified further by Guzik and Kopyciński. ${ }^{[8]}$ Nevertheless, for irregular eutectics, the branching stiffness of the faceted phase gives rise to the formation 
of a truly three-dimensional (3-D) eutectic microstructure, where a governing theory for assessment of pattern selection criteria and microstructure characteristics is still missing. ${ }^{[9]}$

In hypoeutectic $\mathrm{Al}-\mathrm{Si}$ alloys, the $\alpha$-Al primary can be refined efficiently by means of $\mathrm{TiB}_{2}$ inoculation. In addition, further improvements in cast component performance are available through modification of the eutectic microstructure, either by employing a high cooling rate or by relatively modest melt additions of certain elements such as $\mathrm{Sr}, \mathrm{Na}, \mathrm{Sb}$, or $\mathrm{Ca}^{[10-12]}$ Evidently, chemical modification leads to a refinement of the eutectic by converting the relatively coarse and platelike $\mathrm{Si}$ crystals into a much finer and fibrous network. ${ }^{[11,13]}$ However, there are still unsettled issues concerning how these chemical modifiers actually work in combination with other minor constituents to affect the relevant nucleation and growth mechanisms. ${ }^{[10-16]}$

The development of theory and models to describe pattern selection in regular eutectics ${ }^{[4-6]}$ has heavily relied on in-situ experimental observations with transparent alloys, ${ }^{[5,17-19]}$ which was decisive for identifying and characterizing dynamic instabilities that limit the range of stable growth. Fischer and $\mathrm{Kurz}^{[1]}$ also found use of transparent alloys, succinonitrile-borneol and camphor-naphthalene, as model systems for nonfaceted/ faceted growth in their first attempts to adapt the Jackson-Hunt model to irregular eutectics. Nevertheless, in the case of nonfaceted/nonfaceted eutectic growth, there are several transparent systems available as models for studies of the morphology and evolution of single- and multiple-phase fronts. For nonfaceted/ faceted growth systems, however, the situation is more difficult since the analogy of the transparent model to the alloy system also concerns the specific crystallographic anisotropy of the faceted phase, in addition to multiple growth and nucleation mechanisms.

The study reported here is the first attempt at obtaining relevant real-time experimental information on eutectic growth in Al-Si-based systems by X-ray transmission video microscopy during directional solidification (DS) experiments in a Bridgman furnace. Over the last decade, an increasing number of real-time X-ray imaging studies of solidification microstructures and phenomena in real metals have been reported, addressing a broad variety of topics such as dendritic growth ${ }^{[20-23]}$ coarsening, ${ }^{[24]}$ morphological transitions, ${ }^{[23]}$ dendrite fragmentation, ${ }^{[25-27]}$ solute diffusion and convection, ${ }^{[22,28]}$ and momentum transfer relations in eutectics ${ }^{[29]}$ and monotectics. ${ }^{[30]}$ Most of these, and other recent in-situ studies, have been carried out with high-brilliance synchrotron radiation, where X-ray absorption- and near-field phase contrast is combined to bring about $2-\mathrm{D}$ or $3 \mathrm{D}$ time-resolved data. ${ }^{[20-27,29,30]}$

\section{EXPERIMENTAL}

A major challenge with X-ray studies in a standard commercial Al-Si alloy is that practically no absorption contrast would be available at X-ray energies allowing for appreciable transmission through any meaningful sample thickness since the $\mathrm{K}$ X-ray absorption edges for $\mathrm{Al}$ and $\mathrm{Si}$ are close and at low energies, 1.56 and $1.84 \mathrm{keV}$, respectively. ${ }^{[31]}$ On the other hand, phase contrast is possible at useable X-ray energies but would limit the image information to solid-liquid and solidsolid phase boundaries, where reasonably steep gradients in the X-ray optical densities can be used. Phase contrast imaging was recently used to carry out a study of primary dendrite fragmentation in Al-7 pet $\mathrm{Si}$ alloys. ${ }^{[32]}$ Yet, since the direct appearance of phase contrast in the radiograms will be in terms of interference, requiring mathematical reconstruction to arrive at the true spatial form of the contrast object, a wellrefined eutectic would be a very challenging contrast object even after image processing, and real-time on-line monitoring during growth would be impaired.

An alternative approach is to alloy the Al-Si eutectic with an element that can serve as an agent to generate $\mathrm{X}$-ray absorption contrast. Obviously, there are other selection criteria to consider besides provision of absorption contrast. First, any suitable element will be heavier than $\mathrm{Al}$ and $\mathrm{Si}$, since $\mathrm{X}$-ray absorption is associated with core-level photoelectric excitation. Potentially, this implies challenges with respect to mesoand macroscopic sergregation in the sample, which generally shortens the sample lifetime. Second, at the concentration level applied, the contrasting element, X, should not form any stable or metastable phases with Al or $\mathrm{Si}$ at temperatures above the $\mathrm{Al}-\mathrm{Si}-\mathrm{X}$ ternary eutectic reaction. Finally, in order to be of any use in studies of eutectic modification, the contrasting agent should not itself work as a eutectic modifier, be reactive toward potential nucleation sites, or form phases with any of the modifying elements. Three potential contrasting agents are $\mathrm{Cu}, \mathrm{Ag}$, and $\mathrm{Ge}$, with $\mathrm{Cu}$ selected as the initial candidate for the experiments reported here.

The alloys were prepared from high-purity $\mathrm{Al}, \mathrm{Cu}, \mathrm{Si}$, and $\mathrm{Sr}$, molten in an alumina crucible, and cast in an insulated bottom-chilled mold. Two alloys were made with compositions along the ternary eutectic groove, Al-8 wt pet Si-15 wt pet Cu (nonmodified) and Al-9 wt pet $\mathrm{Si}-15$ wt pet $\mathrm{Cu}-0.015$ wt pet $\mathrm{Sr}$ (Sr modified), respectively. Samples were taken from sections of the castings, approximately $1 \mathrm{~cm}$ from the chill and cut into $25 \times 12 \mathrm{~mm}^{2}$ rectangular slabs that were polished down to thicknesses of $135 \pm 5 \mu \mathrm{m}$. Thereafter, the samples were oxidized for 2 hours at $750 \mathrm{~K}\left(477^{\circ} \mathrm{C}\right)$ and put in quartz-glass containers employing techniques and procedures established previously. ${ }^{[20,22,27,30]}$

The experiments were carried out at the micro-optics test bench ${ }^{[33]}$ on beamline ID6 at the European Synchrotron Radiation Facility (ESRF). ID6 is located at a high-beta section undulator, which provides optimal conditions for fast real-time high-resolution X-ray absorption and phase contrast imaging. The experimental equipment and procedures were virtually identical to those used in all our previous in-situ X-ray imaging studies of DS, and interested readers should consult previous work for further details. ${ }^{[20,22,27]}$ However, in the current experiment, a SensiCam QE CCD camera with a $1376 \times 1040$ pixel array, 12 bit dynamic range, and $16 \mathrm{MHz}$ pixel readout was used. The pixel readout 
corresponds to a camera dead time between consecutive frames of $\sim 90 \mathrm{~ms}$. In the particular configuration employed, the camera was mounted with 10 times magnifying optics that gave an effective pixel size of $\sim 0.64 \mu \mathrm{m}$. A total of 12 solidification sequences were collected, 6 with each alloy, using temperature gradients in the range 15 to $45 \mathrm{~K} / \mathrm{mm}\left({ }^{\circ} \mathrm{C} / \mathrm{mm}\right)$, cooling rates in the range 0.14 to $1 \mathrm{~K} / \mathrm{s}\left({ }^{\circ} \mathrm{C} / \mathrm{s}\right)$, and frame grabbing rates of 6.25 to $7.15 \mathrm{~Hz}$.

\section{RESULTS AND DISCUSSION}

\section{A. Al-Si Eutectic Growth in Al-Si-Cu Alloys}

Figure 1 shows eutectic growth in an unmodified sample, DS antiparallel with gravity, g. The frames were collected with an exposure time of $70 \mathrm{~ms}$, which together with the camera readout combined to a time elapse per frame of $\Delta t=160 \mathrm{~ms}$. The images shown are every 15 th frame from a part of the full 354-frame video sequence, selected to illustrate some of the observations on $\mathrm{Al}-\mathrm{Si}(\mathrm{Cu})$ eutectic growth dynamics. Despite being indistinguishable in terms of contrast, $\alpha-\mathrm{Al}$ and $\mathrm{Si}$ crystals are easy to identify by their distinct interface morphologies and substantially different growth dynamics. $\alpha$-Al grows as dendrites with relatively constant interface velocities $\| \mathbf{G}$, roughly corresponding to the DS sample velocity, $v_{s}$. Simultaneously, new faceted $\mathrm{Si}$ needles are seen to form deeper in the mush at a higher solute supersaturation, initially shooting off with high velocities substantially above $v_{s}$, and then gradually decelerating as the growing needle consumes the local melt supersaturation. The first frames in Figure 1 show four $\mathrm{Si}$ crystals growing into the melt, leading the eutectic interface. The crystals grow in different directions, from almost parallel to the imposed temperature gradient, $\mathbf{G} \|-\mathbf{g}$, to an angle $\sim 70 \mathrm{deg}$ counterclockwise with respect to $\mathbf{G}$. By comparing the frames, it can be seen that the four crystal tips propagate under different and nonstationary growth conditions, presumably adapting to changes in the local melt supersaturation. It should be noticed that although at least two of the crystals (the one that originates furthest to the left, and the one growing at the largest angle to $\mathbf{G}$ ) attain what appears to be a more platelike morphology deeper into the mush, the fronts typically progress with needleshaped tip morphologies. This is found to be prevalent for Si crystals growing close to the eutectic interface in the unmodified alloys and is presumed to relate to a substantial solute undercooling at the Si-crystal tips where both $\mathrm{Cu}$ and $\mathrm{Al}$ partition are negligible. It is also interesting to note that some of the $\mathrm{Si}$ crystals growing at larger angles with respect to $\mathbf{G}$, and thereby in directions pointed more into the mush, are found to be more platelike. Yet, during rapid growth, their tips tend to attain shapes more similar to those of parallel needles, as shown by the crystal growing into the image from the right-hand side at $t=9.6$ to 21.6 seconds, indicating the progress of the $\mathrm{Si}$-crystal interface to be restricted mainly by solute diffusion. In the latter part of the sequence, several new $\mathrm{Si}$ needles can be tracked as they form on the pre-existing eutectic colonies and grow to fill parts of the intercolonial volume. Throughout the entire sequence, $\mathrm{Al}$ is seen to form on the Si network and grow nonfaceted, predominantly with dendritic morphologies. Over the relevant ternary eutectic freezing range, $\mathrm{Cu}$ solubility in $\alpha-\mathrm{Al}$ is only $1 / 3$ or less of the nominal $\mathrm{Cu}$ concentration of the melt, $\mathrm{C}_{0}(\mathrm{Cu})$, and accordingly appreciable $\mathrm{Cu}$ rejection occurs also at the $\alpha$-Al-dendritic interface.

Figure 2 shows the evolution of eutectic colonies in another sample with the same nominal unmodified composition (Al-8 wt pet Si-15 wt pet $\mathrm{Cu}$ ), but from the third consecutive DS experiment with $\mathbf{G} \| \mathbf{g}$. The images presented have been selected from a 361-frame sequence, collected with $\Delta t=160 \mathrm{~ms}$. Because of the repeated cycles of solidification and remelting, negative macrosegregation has developed in the sample region studied and made the local composition hypereutectic, evidenced by the presence of two faceted primary $\mathrm{Si}$ crystals. These crystals formed prior to their appearance in the camera field of view, i.e., at higher temperatures, presumably already inside the hot compartment of the Bridgman furnace, which operated at $858 \mathrm{~K}\left(585^{\circ} \mathrm{C}\right)$. From the frames of Figure 2, as the eutectic front approaches the primary $\mathrm{Si}$ crystals (at $t=0$ to 1.6 seconds and 8 to 9.6 seconds), new nonfaceted Al crystals nucleate at the interfaces of the Si crystals and grow as dendrites into the intercolonial melt. From the eutectic colonies, new $\mathrm{Si}$ needles form at the primary $\mathrm{Si}$ crystals or pre-existing needles, and shoot off in different directions, filling intercolonial volume in a rather chaotic manner.

Although not shown explicitly herein, faceted growth of primary $\mathrm{Si}$ was observed with the same sample in a sequence prior to the one shown in Figure 2 during DS of a sample region where the local composition had changed to become just slightly hypereutectic. During the video sequence, about 30 small Si crystals formed at temperatures up to $10 \mathrm{~K}\left({ }^{\circ} \mathrm{C}\right)$ above the eutectic interface and grew faceted into the melt. All crystals remained in fixed positions, indicating that primary $\mathrm{Si}$ nucleation predominantly occurred on the sample oxide surface or on the quartz container walls, since free $\mathrm{Si}$ crystals would be subjected to buoyant forces from a considerably denser Cu-containing melt. If the melt is in direct contact with the container, it will gradually reduce the quartz, resulting in release of $\mathrm{Si}$ into the melt. ${ }^{[20]}$ Over time, both reactions between melt and container and sample segregation can contribute to local variations in the composition.

To shed some more light on the potential mechanisms involved in sample segregation, it is convenient to point at some of the particular microstructure and mushy zone features promoted by the $\mathrm{Cu}$ alloying. The ternary eutectic microstructure is substantially more intricate and morphologically detailed than the typical binary irregular eutectic, where the facetted phase leads the eutectic reaction front and is interconnected via a massive semiplanar nonfacetted component. ${ }^{[1,7,8]}$ As a result, the ternary eutectic mush becomes considerably deeper with liquid pockets that remain open until the $\mathrm{Al}-\mathrm{Al}_{2} \mathrm{Cu}$ eutectic solidifies. In the $\mathbf{G} \| \mathbf{g} \mathrm{DS}$ geometry, 

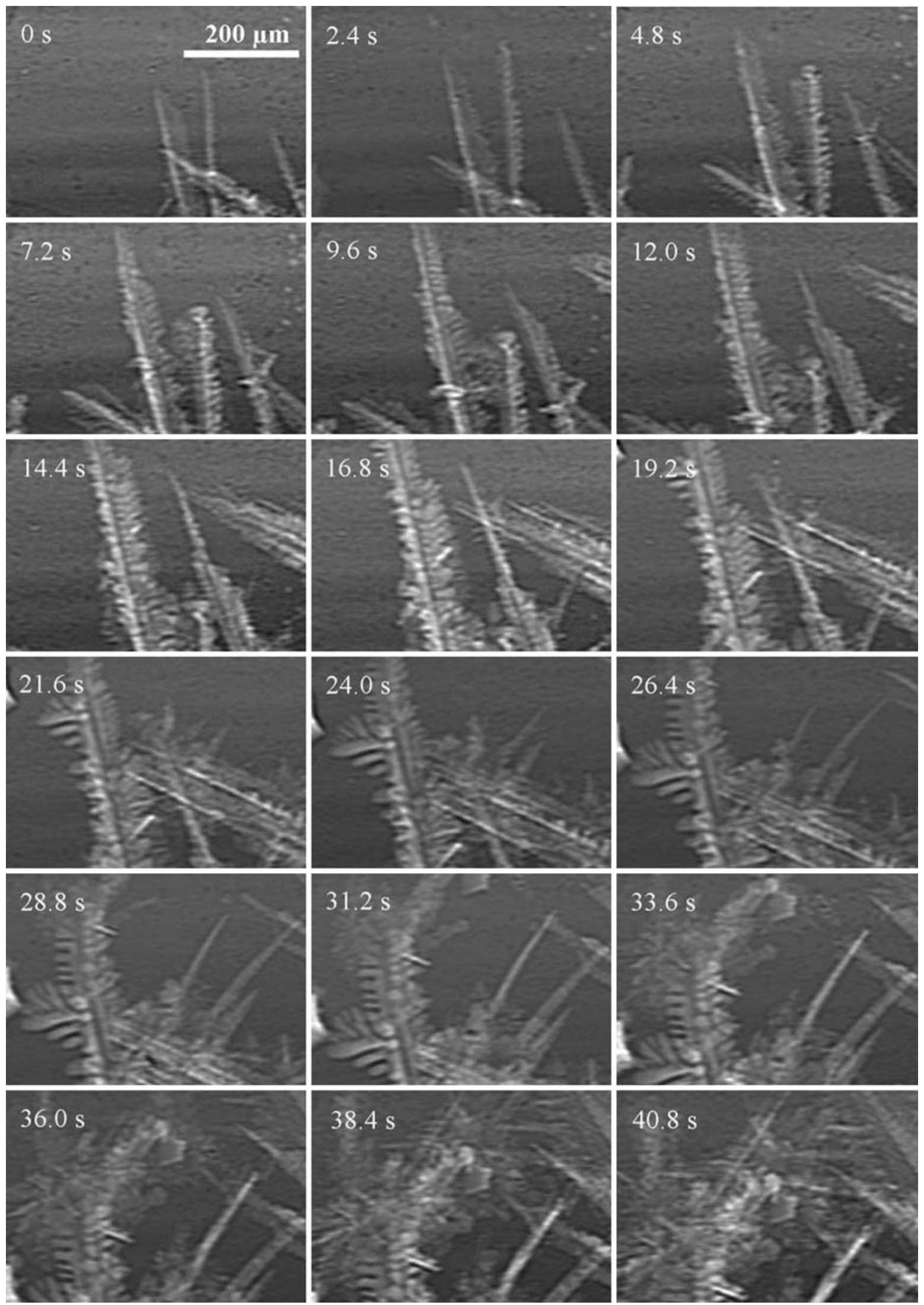

Fig. 1-Unmodified irregular eutectic microstructure formation during DS antiparallel to $\mathbf{g}$ of Al-Si-Cu alloy. $G=25.5 \mathrm{~K} / \mathrm{mm}\left({ }^{\circ} \mathrm{C} / \mathrm{mm}\right)$, $v_{s}=21 \mu \mathrm{m} / \mathrm{s}$, and $\Delta t=160 \mathrm{~ms}$. Times given in the upper left of each image are relative to the first frame of the figure $(0 \mathrm{~s})$. 
$\mathrm{Cu}$ rejection at the $\mathrm{Al}-\mathrm{Si}$ eutectic front gives rise to a densification of the local melt, with subsequent segregation by settling of the heavier melt out of the mush. This may gradually cause macrosegregation of the sample, depending on which mechanisms are active in mixing the $\mathrm{Cu}$-enriched liquid with the $\mathrm{C}_{0}$-bulk melt (convection, shear flow, diffusion, etc). In the $\mathbf{G} \|-\mathbf{g} \mathrm{DS}$ geometry, segregation is considerably more intricate.
Here, $\mathrm{Cu}$-densified melt settles into the mush, where any mixing melt hydrodynamics are damped by permeability and sample confinement, thereby promoting macrosegregation in the sample cell with repeated DS experiments. In addition, the solute enrichment of mush melt could cause local remelting of the Al-Si eutectic, with potential detachment of fragments from the fine dendrite network, as documented in several previous
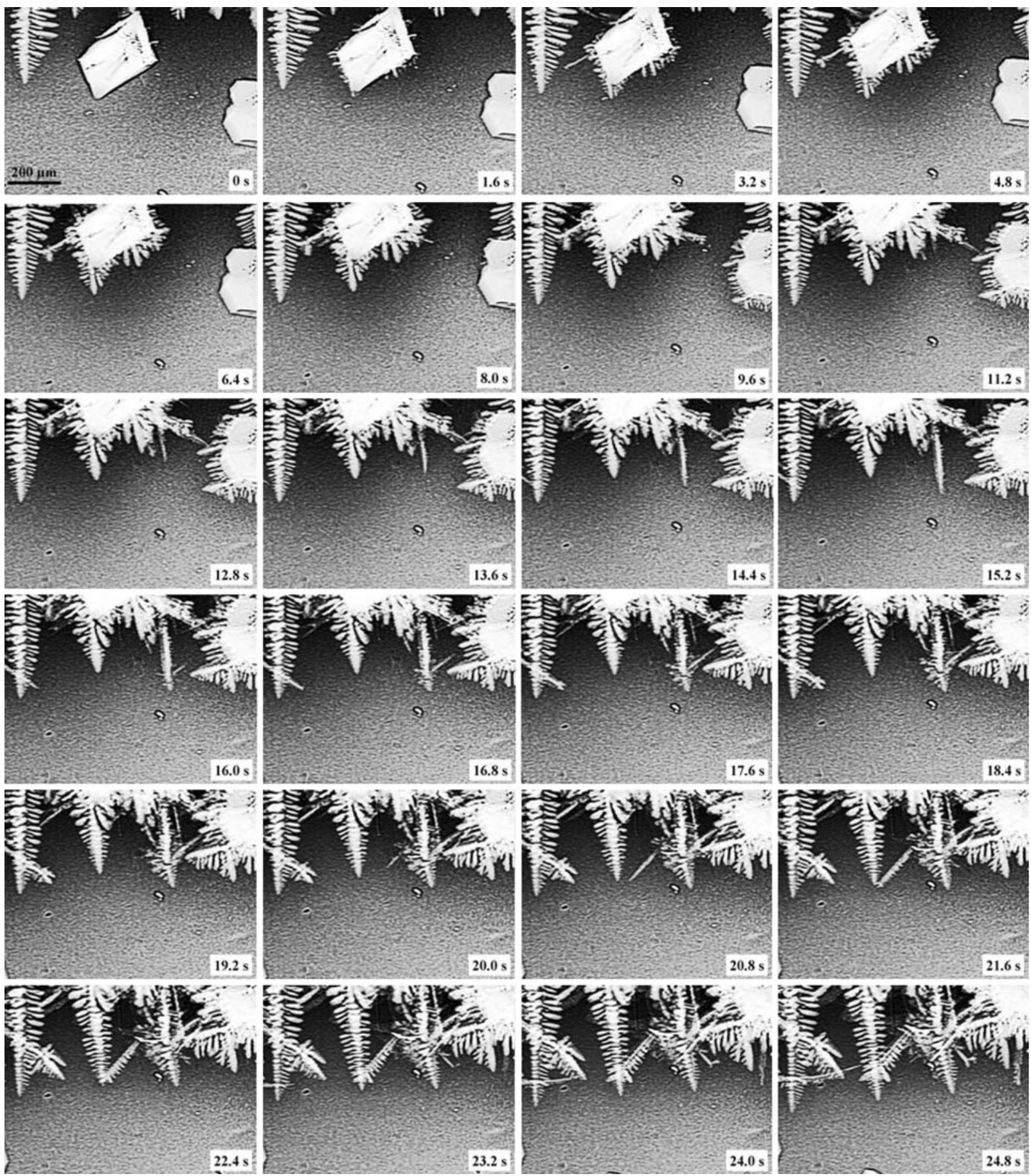

Fig. 2-Unmodified irregular eutectic microstructure formation during $\mathrm{DS}$ parallel to $\mathrm{g}$ of $\mathrm{Al}-\mathrm{Si}-\mathrm{Cu}$ alloy. $G=23.0 \mathrm{~K} / \mathrm{mm}\left({ }^{\circ} \mathrm{C} / \mathrm{mm}\right)$, $v_{s}=17 \mu \mathrm{m} / \mathrm{s}$, and $\Delta t=160 \mathrm{~ms}$. Times given in the images are relative to the first frame of the figure $(0 \mathrm{~s})$. 
studies. ${ }^{[25-27,34]}$ In the relatively open ternary eutectic, both $\mathrm{Al}$ and Si crystals may detach and float out of the mush by buoyancy along the open liquid channels. The free fragments would eventually dissolve in the melt, but since $\mathrm{Al}$ and $\mathrm{Si}$ have different melting entropies and melting temperatures, they would dissolve at different rates and consequentially segregate to different heights relative to the solidification front, causing segregation of the sample at a mesoscopic length scale. Indeed, in one of the DS sequences taken with $\mathbf{G} \|-\mathbf{g}$, detachment of fragments of both $\mathrm{Al}$ and $\mathrm{Si}$ was observed to occur, although considerably less frequently than what has been seen to release from columnar dendrite mushy zones in binary systems. ${ }^{[27,34]}$ In conclusion, over time and with repeated solidification-melting cycles, DS with $\mathbf{G} \|-\mathbf{g}$ can be more detrimental than the $\mathbf{G} \| \mathbf{g}$ geometry in terms of sample segregation.

\section{B. Al-Si Eutectic Microstructures in Sr-Modified $\mathrm{Al}-\mathrm{Si}-\mathrm{Cu}$}

Figure 3 shows results taken from a 350 frame video sequence with the Sr-modified alloy, at $\Delta t=140 \mathrm{~ms}$ and DS with $\mathbf{G} \| \mathbf{g}$. The first image corresponds to the frame exposed at $t=0 \mathrm{~ms}$, the one taken closest in time to where the eutectic reaction could be confirmed to have nucleated based on visual examination of full resolution images. Eutectic nucleation occurred near the secondary branch surface of the rightmost $\alpha$-Al dendrite, in a position roughly in the center of the drawn-in box, at a temperature $\Delta T_{e} \sim \Delta z G=-13 \mathrm{~K}\left({ }^{\circ} \mathrm{C}\right)$ below that at the columnar dendrite tip, with $\Delta z$ as the distance $\|$ $G$ between the eutectic nucleation site and the columnar front. In the following images, showing every 20th frame of the video sequence, a fine coral-like modified eutectic colony forms, gradually evolving into a sixfolded equiaxed cellular rosette. The cellular branches propagate with closely steady tip velocities $\sim v_{s}=11.4 \mu \mathrm{m} / \mathrm{s}$, reasonably uniform in all directions, leaving the rosette to spread evenly over the surface of the $\alpha$-Al dendrite and into the intercolumnar melt regions, eventually bridging over to the nearest neighbor dendrite.

The modified eutectic growth process illustrated in Figure 3 was confirmed by very similar observations from five other DS sequences collected with the same alloy. In all the events where Sr-modified eutectic nucleation occurred within the camera field of view, it appeared very close to the $\alpha$-Al dendrite surfaces, mainly near primary or secondary branches. The density of eutectic nucleation sites was consistently low; throughout the 6 sequences, 25 eutectic colonies were observed to form within the monitored regions. Note that despite a modest field of view, the sequence frames covered temperature regions from $20 \mathrm{~K}$ to $45 \mathrm{~K}\left({ }^{\circ} \mathrm{C}\right)$ due to the relatively high $G$ values employed.

From the six sequences collected with the Sr-containing alloys, the nucleation undercooling for the modified eutectic was found to vary in the range $\Delta T_{e} \sim 6 \mathrm{~K}$ to $15 \mathrm{~K}\left({ }^{\circ} \mathrm{C}\right)$, relative to the temperature of the $\alpha$-Al columnar dendritic front. Due to a temporary problem with fixing the sample in its holder, all DS sequences collected with the Sr-modified alloys were made with
G $\|$ g. Consequentially, fragmentation from the $\alpha$-Al or modified eutectic was avoided, leaving settlement of $\mathrm{Cu}$-enriched liquid out of the mushy zone to be the main source for sample segregation. Thus, segregation in the modified alloys is expected to be modest for the initial sequences, becoming gradually more severe with the number of repeated melting-solidification cycles.

Without fragmentation, the $\mathrm{Al}-\mathrm{Si}$ ratio remains steady, and therefore the $\alpha$-Al columnar dendrite tip temperature is expected to vary between the different DS sequences mainly as a function of the local undercooling at the columnar front relative to an effective $\mathrm{C}_{0}(\mathrm{Si}, \mathrm{Cu})$ concentration typically 2 to 3 diffusion lengths into liquid ahead of the front. The sequence shown in Figure 3 is the second sequence taken with that particular sample, and presuming that the $\mathrm{Cu}$ segregation is modest enough to be neglected, the $\alpha$-Al columnar front undercooling is relative to the $\mathrm{C}_{0}$ tertiary eutectic equilibrium temperature. The columnar tip radius and growth velocity, extracted from images of the sequence prior to the ones shown in Figure 3, are roughly $12 \mu \mathrm{m}$ and $13 \mu \mathrm{m} / \mathrm{s}$, respectively, which, when employing a standard Ivantsov-parabola analysis, suggests a columnar tip undercooling of $\sim 3.5 \mathrm{~K}\left({ }^{\circ} \mathrm{C}\right)$. This would be a typical value for the magnitude of columnar front undercoolings realized in the six sequences with the Sr-modified alloys, which, when added to the measured temperature displacements between the columnar dendrite and eutectic fronts, stipulate the Sr-modified eutectic to nucleate at undercoolings in the range $10 \mathrm{~K}$ to $18 \mathrm{~K}\left({ }^{\circ} \mathrm{C}\right)$ relative to the equilibrium ternary eutectic reaction temperature.

A control experiment was designed to test if the underlying assumptions of a modest segregation and preservation of a near-eutectic local constitution are reasonable. In another DS cycle with the same sample, with identical solidification parameters to the Figure 3 sequence, the $\alpha$-Al and a modified eutectic front were established in the field of view, and then the sample motion was stopped. After a few seconds of transient growth, the $\alpha$-Al front came to a halt and proceeded with a slow back melting. At the same time, the modified eutectic continued to solidify. The image shown in Figure 4 was collected after a few minutes of holding time, where the fibrous coral-like eutectic microstructure had grown to cover the entire surface of the $\alpha$-Al crystal. Clearly, the local alloy constitution remains closely eutectic through a few repeated cycles of solidification and remelting, and eventual modest shifts in the local bulk liquid $\mathrm{Cu}$ content with respect to $\mathrm{C}_{0}$ should not have a pronounced effect on the columnar tip and eutectic nucleation undercooling.

In several sequences, the growth morphology of isolated modified eutectic cells was found to evolve from spherical or disc-like eutectic envelopes in the initial stages to more cellular forms, like the one displayed in Figure 3. The cellular envelopes evolved in a similar manner to single-phase microstructures when the nucleation density is modest, i.e., more equiaxed the further away from neighboring grains. Figure 5 is a magnified close-up of the box region drawn in Figure 3 at $t=22.6$ seconds, where finer 

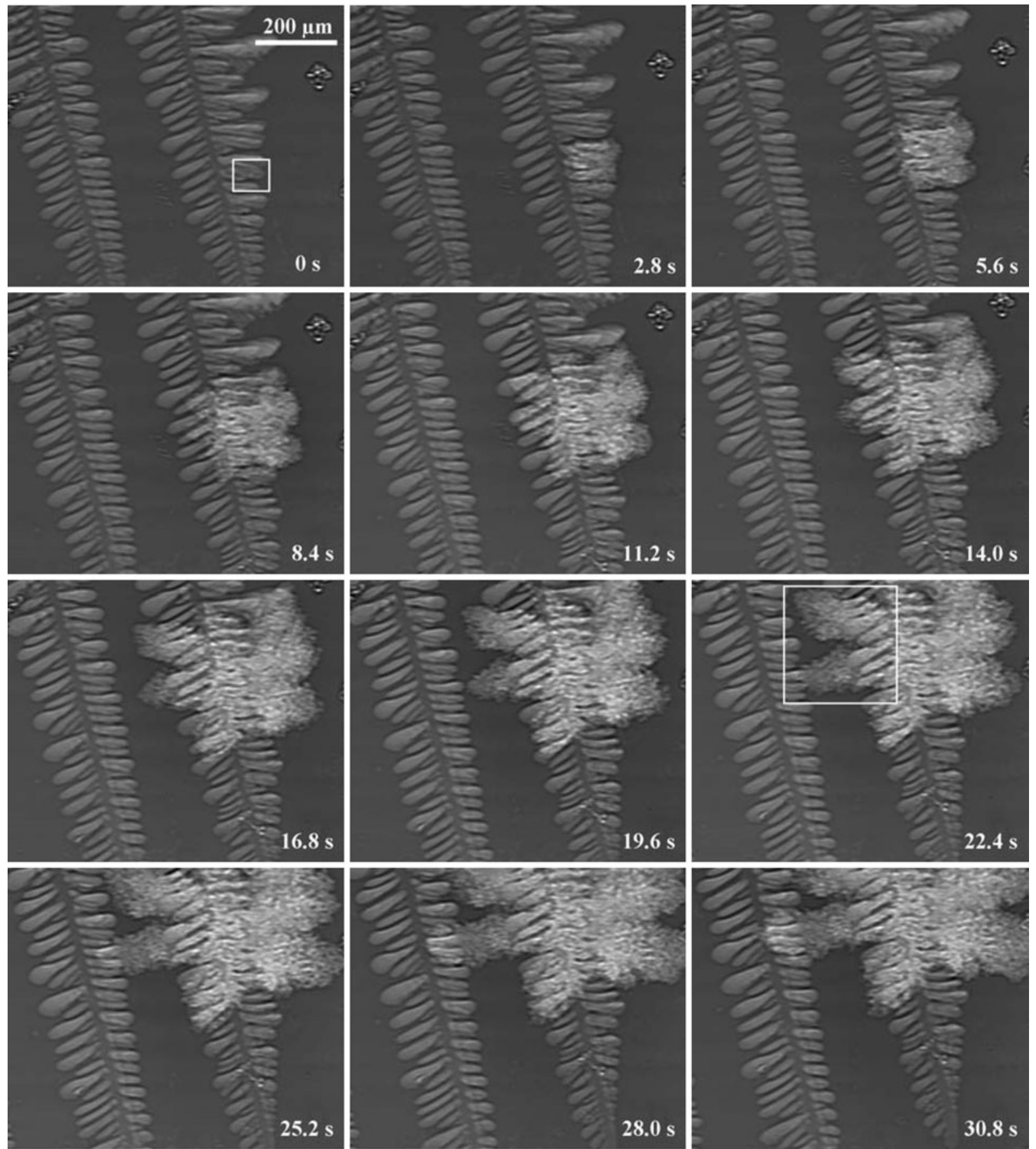

Fig. 3-Sr-modified irregular eutectic microstructure formation during DS parallel to $\mathrm{g}$ of $\mathrm{Al}-\mathrm{Si}-\mathrm{Cu}-\mathrm{Sr}$ alloy. $G=18.4 \mathrm{~K} / \mathrm{mm}\left({ }^{\circ} \mathrm{C} / \mathrm{mm}\right)$, $v_{s}=10.5 \mu \mathrm{m} / \mathrm{s}$, and $\Delta t=140 \mathrm{~ms}$. Times given in the images are relative to the first frame of the figure $(0 \mathrm{~s})$.

morphological details at the modified eutectic fronts are more visible. It is not possible to resolve directly from the images whether these are faceted fibers/needles or nonfaceted fingerlike, and without any constitutional information from the X-ray transmission contrast, there are no routes available directly from image analysis to distinguish between the two eutectic phases. Yet, since the partition of $\mathrm{Cu}$ into the two constituent phases differs from closely zero in Si to a few weight percent in
$\alpha-\mathrm{Al}$, more $\mathrm{Cu}$ has to be rejected ahead of the faceted $\mathrm{Si}$, leaving the latter to grow at a higher solute undercooling. Thus, at a first glance, it seems reasonable to assume the features with positive curvatures to be $\mathrm{Si}$.

Clearly, the alloying with $\mathrm{Cu}$ influences the growth dynamics and morphologies of the Sr-modified eutectic, in particular through mesoscopic scale perturbations of the composite interface linked to a long-range redistribution of $\mathrm{Cu}$ into the mush liquid. However, it is not 


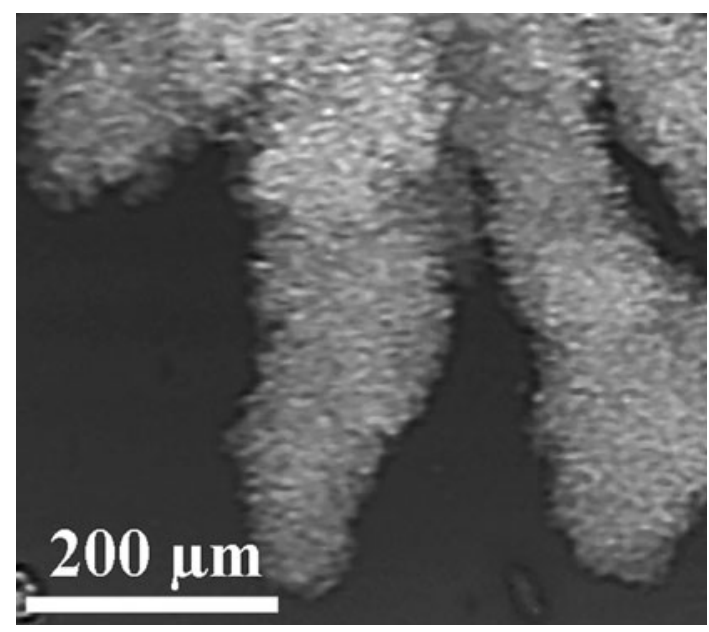

Fig. 4-Sr-modified eutectic microstructure covering the $\alpha$-Al dendrite network in the $\mathrm{Al}-\mathrm{Si}-\mathrm{Cu}-\mathrm{Sr}$ alloy.

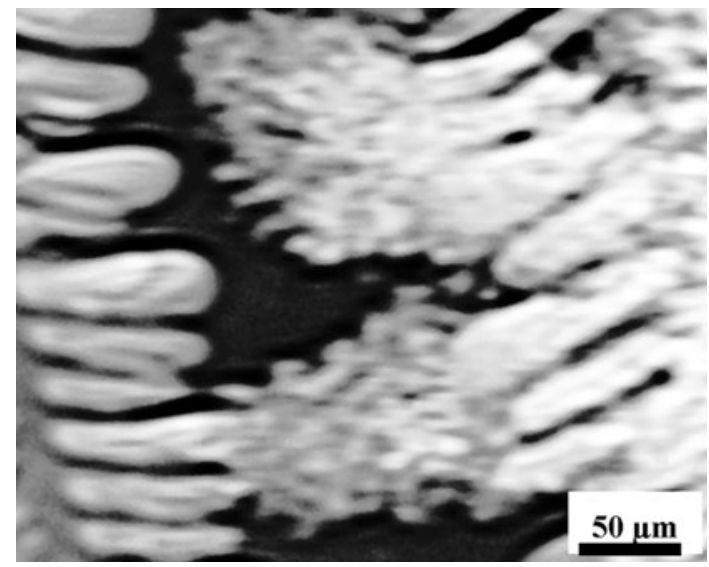

Fig. 5-Close-up of the Sr-modified eutectic solid-liquid interface from the white box region of the $22.4 \mathrm{~s}$ frame in Fig. 3.

clear to what extent the far-field $\mathrm{Cu}$ transport has an influence on the short length-scale redistribution profiles, decisive in forming the modified $\mathrm{Al}-\mathrm{Si}$ eutectic microstructure. Under circumstances where third element alloying is found to have a strong impact on the short-range eutectic microstructure, X-ray contrast element alloyed systems may be of limited interest as analogues to commercially relevant systems. The current resolution limit of our experiment does not allow for an evaluation of these aspects from the live X-ray images. In order to investigate the short length scale appearance of the modified eutectic microstructures shown in Figures 3 to 5 , another sample was prepared using the same furnace and DS parameters as those employed for the sequence shown in Figure 3. After repetition of the DS experiment, the sample was subjected to soft quenching by removing the sample from the furnace. A representative sample region was selected and prepared for optical microscopy. Figure 6 shows typical micrographs taken at different magnifications. Figure 6(a) is centered on a columnar $\alpha$-Al dendrite, partly covered by a fine Al-Si eutectic, similar to the

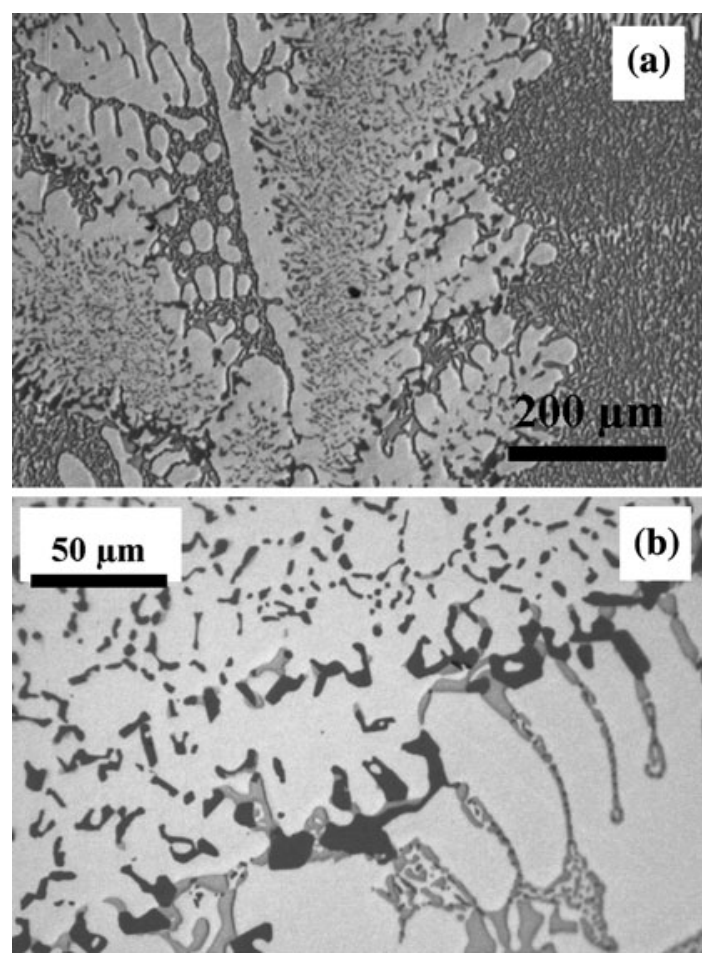

Fig. 6-Micrographs taken from Sr-modified Al-Si-Cu samples after DS parallel to $\mathbf{g}$, with $G=18.4 \mathrm{~K} / \mathrm{mm}\left({ }^{\circ} \mathrm{C} / \mathrm{mm}\right)$ and $v_{s}=10.5 \mu \mathrm{m} / \mathrm{s}$, followed by a soft quenching. Phase constituents are displayed as follows: $\mathrm{Si}$ (dark gray), $\theta-\mathrm{Al}_{2} \mathrm{Cu}$ (light gray), and $\alpha-\mathrm{Al}$ (bright).
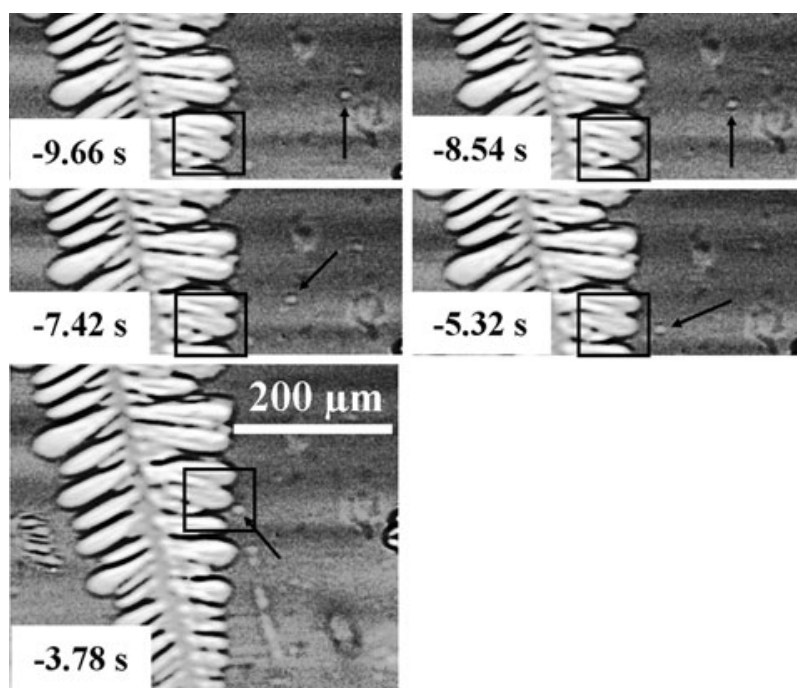

Fig. 7 - Close-ups showing Si particle motion prior to eutectic nucleation during DS parallel to $\mathbf{g}$ in $\mathrm{Al}-\mathrm{Si}-\mathrm{Cu}-\mathrm{Sr}$. The images are taken from the same sequence as the one used in Fig. 3 with $G=18.4$ $\mathrm{K} / \mathrm{mm}\left({ }^{\circ} \mathrm{C} / \mathrm{mm}\right), v_{s}=10.5 \mu \mathrm{m} / \mathrm{s}$, and $\Delta t=140 \mathrm{~ms}$. Times given are relative to the eutectic nucleation event occurring at $t=0 \mathrm{~s}$.

microstructure shown in Figure 4. Furthermore, a relatively fine $\mathrm{Al}-\mathrm{Al}_{2} \mathrm{Cu}$ is seen to have formed in the interdendritic liquid regions as well as in tiny liquid volumes between the higher order dendrite branches. Figure 6(b) shows a close-up of a region showing all three archetype microstructures, demonstrating a fibrous Si-type 
modified eutectic microstructure similar to those found in castings with Sr-modified binaries or industrial variants. ${ }^{[10-13]}$

Finally, with the presence of $\alpha$-Al dendrites as well as other eutectic colonies, modified eutectic growth may be restricted by other factors in addition to interface capillarity and free diffusive transport into the nearand far-field nominal melts. Prior to complete solidification of the remaining $\mathrm{Cu}$-enriched liquid, continuous change with temperature in the $\alpha$-Al $\mathrm{Cu}$ solubility, combined with dendrite coarsening, will cause local constitutional variations in the liquid, and possible dendritic-eutectic and eutectic-eutectic mass transfer, where the difference in melting and freezing kinetics between the different constituents also could be of importance. In particular, such effects should be taken into account for late stage eutectic solidification deep in the mush or when nearby eutectic crystals experience soft impingement via overlap of their solute diffusion fields.

\section{Eutectic Nucleation in the Sr-Modified Alloys}

Despite other discrepancies, existing nucleation hypotheses for the Sr-modified eutectic unify in assuming eutectic microstructure formation to proceed immediately upon precipitation of $\mathrm{Si}^{[10-16]}$ With eutectic nucleation observed to occur exclusively in the vicinity of the $\alpha-\mathrm{Al}$ dendrite surface, it therefore at a first glance seems reasonable to assume some form of correlation to exist between the $\mathrm{Si}$ nucleation mechanism and the presence of $\alpha$-Al. Such a correlation would be in favor of Si nucleation on chemically potent sites situated at the $\alpha$-Al surface, or alternatively on potent intermetallic particles formed in the impurity-element enriched melt very close to the dendrite surface..$^{[11-16]}$ To shed more light on the relationship between formation of the eutectic, presence of $\alpha-\mathrm{Al}$, and crystallization of the first $\mathrm{Si}$, the video sequence illustrated in Figure 3 was reconstructed from images subjected to additional contrast enhancement operations. In this video, it was possible to locate and follow the motion of a $\sim 10-\mu \mathrm{m}$ size particle over a sequence of 70 frames or 9.8 -second duration.

The particle motion is illustrated in Figure 7 by a selection of regional close-ups from full-sized images. The particle, pointed to by the arrow, appears in a region situated in the rightmost intercolumnar melt in Figure 3, about 10 seconds prior to eutectic formation. The particle can be tracked as it moves toward the eutectic nucleation site, which also here has been indicated by box regions in each frame over the location were eutectic eventually forms (at $t=0$ seconds in Figure 3). At $t=-3.78$ seconds, the particle has reached the rightmost dendrite of Figure 3 and is seen inside the box region just before it disappears from the projection images as it superpositions with the equally $\mathrm{X}$-ray transparent $\mathrm{Al}$ dendrite. Judging from the particle motion, its final location with respect to the $\alpha-\mathrm{Al}$ dendrite, and the eutectic nucleation site in Figure 3 , it is reasonable to assume that the eutectic colony nucleates on the particle, which presumably is a small $\mathrm{Si}$ crystal that has formed on a potent site freely suspended in the melt. If our assumptions are correct, the observation in Figure 7 provides new and unique insight into how eutectic formation may occur in Sr-modified alloys. Apparently, crystallization of $\mathrm{Si}$ is not in itself enough to facilitate the eutectic transformation. The undercooling condition required for $\mathrm{Al}$ to start forming at the $\mathrm{Si}$ particle interface is probably more readily available in the solute-enriched melt surrounding the $\alpha$-Al dendrites. Actually, this is in quite good agreement with the observations in the unmodified system shown in Figure 2, where halo formation of $\mathrm{Al}$ on the primary $\mathrm{Si}$ crystals did not occur before the latter became exposed to the solute boundary of the $\alpha$-Al dendrite front.

We have not yet been able to confirm the observation in Figure 7 with similar events in any of the other sequences with the Sr-modified alloys. However, detection and tracking of such small and moving pre-eutectic particles is extremely difficult and not even possible when their trajectories superimpose with the image projection area of the $\alpha$-Al dendrite network. Therefore, it may be that the discovered mechanism is responsible for nucleating all or just a subset of the 25 Sr-modified eutectic colonies observed. It is not possible, by either $\mathrm{X}$-ray contrast or particle morphology, to provide any hard evidence for the particle being a Si crystal. Yet, assuming so would be in accordance with the present hypotheses of $\mathrm{Sr}$ preventing or retarding $\mathrm{Si}$ nucleation either by impurity-induced twinning ${ }^{[10]}$ or by promoting precipitation of intermetallics with low potency as $\mathrm{Si}$ inoculants. ${ }^{[11-16]}$ Furthermore, it has been possible to find supporting evidence from one of the $\mathbf{G} \|-\mathbf{g}$ DS sequences collected with the unmodified alloys, where two $\mathrm{Si}$ crystals were observed to precipitate from the bulk melt. These crystals could be followed as they moved and grew, initially in swirling motion inside the eutectic mush. As they grew in size, the buoyancy exerted on them from the denser melt increased and became dominant over Stokes drag and other local mushy zone flow, and finally the crystals floated up through the mush and out of the camera field of view, toward higher temperatures. Before leaving the monitored region, however, the crystals had time to evolve into sizes up to $100 \mu \mathrm{m}$, with pronounced faceted morphologies. It is also noteworthy to emphasize that although these two Si crystals formed and grew in liquid regions inside the eutectic mushy zone, the eutectic reaction did not initiate at their interfaces.

The particle motion in Figure 7, which predominantly is in the horizontal direction, must be driven by melt flow present in the sample cell. Such hydrodynamic flow fields can easily develop over length scales that extend far beyond our relative small field of view, which covers only about $1 / 300$ of the full sample volume and where typically half or more would be molten. It is recognized that thermosolutal convection is promoted in the $\mathbf{G} \| \mathbf{g}$ DS geometry. Typically, the combination of a cool, heavier solute-enriched melt settling from the solidification front and heat flow into the system from below can give rise to macroscopic convection rolls with buoyant flow along the thermal centerline of the sample and settling flow at the sample edges. We have evidenced the 
presence of such flow in our cells with DS and $\mathbf{G} \| \mathbf{g}$, both in $\mathrm{Al}-\mathrm{Cu}$ and $\mathrm{Al}-\mathrm{Si}-\mathrm{Cu}$ samples, by tracking the velocity field of the solute boundary layer in the liquid ahead of columnar dendritic fronts. ${ }^{[22,34,35]}$

During the video sequences, all the eutectic colonies observed remained fixed in position with respect to the $\alpha$-Al dendrite network, at least within the limits of resolution. This observation implies that eutectic colonies nucleate only when Si particles are located so close to the primary $\alpha$-Al surface that the colonies more or less immediately entangle in the dendrite network. Eventual eutectic colonies nucleating on particles suspended deeper into the mush liquid should be subjected to appreciable buoyant transport, as the density difference between a eutectic colony and the $\mathrm{Cu}$-enriched melt is $\sim 1 \mathrm{~g} / \mathrm{cm}^{3}$ or more at the nucleation temperatures involved. Assuming early-stage eutectic colonies to attain spherical morphologies and their growth rates to remain $\sim 10 \mu \mathrm{m} / \mathrm{s}$, corresponding to typical observed growth velocities of developed rosettes, entanglement of free colonies should have to occur within the first second of growth. In the absence of any other flow, a colony diameter of $10 \mu \mathrm{m}$ is about the limiting spherical particle size where Stokes drag becomes inadequate to balance the buoyancy force.

In principle, modified eutectic nucleation could occur on the walls of the sample container. Yet, in that case, some colonies should also be found to form in the interdendritic regions, and such observations were not made. Nucleation on the container wall does not seem to be appropriate to explain eutectic morphologies such as the ones shown in Figure 4, which clearly indicate that there is a strong correlation between the loci of eutectic colonies and the dendrite network.

It should however be noted that since the $\mathrm{AlSiCuSr}$ alloys used in this work have been produced from highpurity master alloys, the observations made do not exclude eutectic nucleation on $\mathrm{Si}$ particles suspended deeper in the enriched melt from being considerably more prominent in alloys with higher impurity levels. It is also not entirely clear to what extent the melt $\mathrm{Cu}$ concentration in itself affects the nucleation. Nevertheless, despite the fact that observations made here point toward new discoveries, i.e., that $\mathrm{Si}$ nucleation alone is not adequate to from the eutectic, there is nothing in our results that contradicts the findings made in these earlier studies of post-solidified microstructures. ${ }^{[1-16]}$ The difference simply concerns the dynamical behavior of the system prior to eutectic nucleation and is an observation that would be quite impossible to make without in-situ insight into the microstructure formation process.

\section{CONCLUSIONS}

The work reported here has demonstrated the first in-situ observations of the growth of faceted/nonfaceted eutectic alloys of metals, applied successfully in the industrially important Al-Si system. These initial observations show results in accordance with many of those obtained in previous studies of quenched samples, including $\mathrm{Si}$ as the leading phase, epitaxial nucleation of eutectic $\mathrm{Al}$ on $\mathrm{Si}$, and large reductions in eutectic nucleation frequency with smooth solid-liquid interfaces in Sr-containing alloys. In addition, the experiments have provided new insight into eutectic nucleation mechanisms, where it seems that precipitation of $\mathrm{Si}$ alone is insufficient to facilitate the eutectic reaction, also in Sr-modified alloys.

Continued in-situ studies of DS in these and other $\mathrm{X}$-ray contrast providing alloy systems open access to further insight into the governing aspects of microstructure formation and growth in irregular eutectics that could be of great scientific and industrial importance.

\section{OPEN ACCESS}

This article is distributed under the terms of the Creative Commons Attribution Noncommercial License which permits any noncommercial use, distribution, and reproduction in any medium, provided the original author(s) and source are credited.

\section{REFERENCES}

1. D.J. Fischer and W. Kurz: Acta Metall., 1980, vol. 28, pp. 777-94.

2. K.A. Jackson and J.D. Hunt: Trans. TMS-AIME, 1966, vol. 236, pp. $1129-42$.

3. J.S. Langer: Phys. Rev. Lett., 1980, vol. 44, pp. 1023-26.

4. A. Karma and A. Sarkissian: Metall. Mater. Trans. A, 1996, vol. $27 \mathrm{~A}$, pp. $635-56$.

5. M. Ginibre, S. Akamatsu, and G. Faivre: Phys. Rev., 1997, vol. E56, pp. 780-96.

6. A. Parisi and M. Plapp: Acta Mater., 2008, vol. 56, pp. 1348-57.

7. P. Magnin and W. Kurz: Acta Metall., 1987, vol. 35, pp. 1119-28.

8. E. Guzik and D. Kopyciński: Metall. Mater. Trans. A, 2006, vol. 37A, pp. 3057-67.

9. M. Asta, C. Beckermann, A. Karma, W. Kurz, R. Napolitano, M. Plapp, G. Purdy, M. Rappaz, and R. Trivedi: Acta Mater., 2009, vol. 57, pp. $941-71$.

10. S.Z. Lu and A. Hellawell: Metall. Trans. A, 1987, vol. 18A, pp. 1721-33.

11. A.K. Dahle, K. Nogita, J.W. Zindel, S.D. McDonald, and L.M. Hogan: Metall. Mater. Trans. A, 2001, vol. 32A, pp. 949-60.

12. K. Nogita, S.D. McDonald, and A.K. Dahle: Mater. Trans., 2004, vol. 45 , pp. 323-26.

13. G. Heiberg, K. Nogita, A.K. Dahle, and L. Arnberg: Acta Mater., 2002, vol. 50, pp. 2537-46.

14. S. Shankar, Y.W. Riddle, and M.M. Makhlouf: Acta Mater., 2004, vol. 52, pp. 4447-60.

15. S.D. McDonald, K. Nogita, and A.K. Dahle: Acta Mater., 2004, vol. 52, pp. 4273-80.

16. Y.H. Cho, K.H. Oh, H.C. Lee, and A.K. Dahle: Metall. Mater. Trans. A, 2008, vol. 39A, pp. 2435-48.

17. S. Akamatsu, S. Bottin-Rousseau, and G. Faivre: Phys. Rev. Lett., 2004, vol. 93, Article ID 175701.

18. S. Akamatsu, M. Plapp, G. Faivre, and A. Karma: Metall. Mater. Trans. A, 2004, vol. 35A, pp. 1815-28.

19. S. Akamatsu, S. Bottin-Rousseau, M. Perrut, G. Faivre, V.T. Witusiewicz, and L. Sturz: J. Cryst. Growth, 2007, vol. 299, pp. 418-28.

20. R.H. Mathiesen, L. Arnberg, K. Ramsøskar, T. Weitkamp, C. Rau, and A. Snigirev: Metall. Mater. Trans. B, 2002, vol. 33B, pp. 613-23.

21. T. Schenk, H.N. Thi, J. Gastaldi, G. Reinhart, V. Cristiglio, N. Mangelinck-Noel, H. Klein, J. Hartwig, B. Grushko, B. Billia, and J. Baruchel: J. Cryst. Growth, 2005, vol. 275, pp. 201-08. 
22. R.H. Mathiesen and L. Arnberg: Acta Mater., 2005, vol. 53, pp. $947-56$.

23. H. Nguyen-Thi, G. Reinhart, N. Mangelinck-Noel, H. Jung, H.B. Billia, T. Schenk, J. Gastaldi, J. Hartwig, and J. Baruchel: Metall. Mater. Trans. A, 2007, vol. 38A, pp. 1458-64.

24. N. Limodin, L. Salvo, E. Boller, M. Suery, M. Felberbaum, S. Gailliegue, and K. Madi: Acta Mater., 2009, vol. 57, pp. 2300-10.

25. H. Yasuda, I. Ohnaka, K. Kawasaki, A. Sugiyama, T. Ohmichi, J. Iwane, and K. Umetani: J. Cryst. Growth, 2004, vol. 262, pp. 645-52.

26. H. Yasuda, Y. Yamamoto, N. Nakatsuka, M. Yoshiya, T. Nagira, A. Sugiyama, I. Ohnaka, K. Uesugi, and K. Umetani: Int. J. Cast Met. Res., 2009, vol. 22, pp. 15-21.

27. R.H. Mathiesen, L. Arnberg, P. Bleuet, and A. Somogyi: Metall. Mater. Trans. A, 2006, vol. 37A, pp. 2515-24.

28. S. Boden, S. Eckert, B. Willers, and G. Gerbeth: Metall. Mater. Trans. A, 2008, vol. 39A, pp. 613-23.
29. G. Reinhart, A. Buffet, H. Nguyen-Thi, B. Billia, H. Jung, N. Mangelinck-Noel, N. Bergeon, T. Schenk, J. Hartwig, and J. Baruchel: Metall. Mater. Trans. A, 2008, vol. 39A, pp. 865-74.

30. P.L. Schaffer, R.H. Mathiesen, L. Arnberg, M. Di Sabatino, and A. Snigirev: New J. Phys., 2008, vol. 10, Article ID 053001.

31. International Tables for Crystallogrphy Vol. C, A.J. Wilson, ed., Kluwer Academic Publishers, London, 1992, p. 177.

32. H. Jung, N. Mangelinck-Noel, H. Nguyen-Thi, N. Bergeon, B. Billia, A. Buffet, G. Reinhart, T. Schenk, and J. Baruchel: Int. J. Cast Met. Res., 2009, vol. 22, pp. 208-11.

33. A. Snigirev, R. Hustache, P. Duboc, J.-Y. Massonnat, L. Claustre, P. Van Vaerenbergh, I. Snigireva, M. Grigoriev, and V. Yunkin: Proc. SPIE, 2007, vol. 6705, Article ID 670511-1.

34. L. Arnberg and R.H. Mathiesen: JOM, 2007, vol. 59, pp. 20-26.

35. P. Delaleau, C. Beckermann, R.H. Mathiesen, and L. Arnberg: Iron Steel Inst. Jpn. Int. (ISIJ Int.), 2010, vol. 50, in press. 